J. Lake Sci. (湖泊科学), 2016, 28(6): 1381-1390

DOI 10. 18307/2016. 0624

(c) 2016 by Journal of Lake Sciences

\title{
古生态记录揭示的长江中下游太白湖生态系统稳态转换过程”
}

\author{
赵雁捷 ${ }^{1,2}$, 王 荣 $^{1}$, 羊向东 ${ }^{1 * *}$, 董旭辉 ${ }^{1}$, 徐 敏 $^{1,2}$ \\ (1: 中国科学院南京地理与湖泊研究所,南京 210008) \\ (2: 中国科学院大学, 北京 100049)
}

\begin{abstract}
摘 要: 长江中下游浅水湖泊在过去百年内受到强烈的人类活动影响, 生态系统状态发生显著的变化, 服务功能逐渐丧 失. 为了更科学有效地管理浅水湖泊, 当前迫切需要了解湖泊的生态系统转变过程. 以长江中下游典型富营养化浅水湖泊 太白湖为例, 结合历史资料和监测数据, 基于铅脃同位素重建年代序列, 利用粒度、地化指标和沉积物中硅藻群落的时间 序列数据, 对太白湖过去百年间生态系统转变进行分析. 基于 $\mathrm{T}$ 检验的 STARS 法检测硅藻群落的结果显示, 有 2 个稳态转 换分别发生在 1950s 末和 1990s 末. 1950s 末太白湖硅藻群落代表的生态系统状态发生了显著突变, 这主要归因于由于建 闸筑坝造成的水文条件和营养条件的改变; 1990s 期间的湖泊生态系统整体转变则是由长期营养输人和渔业活动加强导 致的生态系统弹性损失引起的. 讨论了不同阶段太白湖生态系统主要要素间反馈机制在水文条件改变和营养富集影响 下的变化,加深了对人类活动干扰下太白湖生态系统结构变化过程的理解,为建立浅水湖泊系统动力学模型提供基础.
\end{abstract}

关键词: 系统突变; 长江中下游; 浅水湖泊;太白湖; 硅藻; 反馈机制

\section{Regime shifts revealed by paleoecological records in Lake Taibai's ecosystem in the mid- dle and lower Yangtze River Basin during the last century}

\author{
ZHAO Yanjie ${ }^{1,2}$, WANG Rong ${ }^{1}$, YANG Xiangdong ${ }^{1 * *}$, DONG Xuhui ${ }^{1} \&$ XU Min ${ }^{1,2}$ \\ (1: Nanjing Institute of Geography and Limnology, Chinese Academy of Sciences, Nanjing 210008, P.R.China) \\ (2: University of Chinese Academy of Sciences, Beijing 100049, P.R.China)
}

\begin{abstract}
Shallow lakes in the middle and lower Yangtze River Basin are greatly influenced by human activities during the last century, subsequently ecological regime shifts have occured and some ecosystem services are degraded in some shallow lakes. In order to provide more scientific and efficient lake management, it is necessarily urgent to understand the transforming process of the lake ecosystems. In this study, we focus on a typical eutrophic shallow lake sited in the middle reach of Yangtze River Basin, namely Lake Taibai, and combine its related geochemistry proxies, grain size and fossil diatom assemblages from a sediment core dated in ${ }^{210} \mathrm{~Pb}$ and ${ }^{137} \mathrm{Cs}$ chronology based on paleolimnology with the basin's historical documents and monitoring data, to analyze specific regime shifts occurred in its ecosystem and changes of feedbacks inside driven by hydrodynamic changes and nutrient enrichement process. Results of diatom assemblages using STARS, a T-test based algorithm, revealed that at least two ecological shifts took place in the late 1950s and 1990s, respectively. The sudden shift in the late 1950s is supposed to be influenced hydrological change caused by dam and sluice constructions in 1950s and another shift in the late 1990s should be a critical transition due to the alternation of cultured fish community and consistent nutrient enrichment, which led to gradual decrease in ecosystem resilience in Lake Taibai. Through analyzing the changes of feedbacks among main function groups in the ecosystem influenced by the change of hydrodynamics and euthrophication, we can have a deeper understand of the process of ecosystem structural changes disturbed by anthropogenic driversand lay the fundation for building a shallow lake ecosystem dynamic model in future researches.
\end{abstract}

Keywords: Regime shifts; middle and lower reaches of Yangtze River Basin; shallow lakes; Lake Taibai; diatom; feedbacks

* 国家自然科学基金重点项目 (41530753) 和国家自然科学基金项目 (41472314) 联合资助. 2015-11 - 10 收稿;201603 - 22 收修改稿. 赵雁捷(1992 ), 女, 硕士研究生;E-mail: yanjiezhao92@163.com.

** 通信作者;E-mail: xdyang@ niglas.ac.cn. 
生态系统状态与外界驱动之间既存在线性关系,也存在非线性关系. 在非线性关系中, 系统状态的变化 存在临界点, 当系统处于临界点附近, 外界驱动的微小变化就可能导致其状态的巨大改变, 会出现一些预料 之外的结果 ${ }^{[1]}$. 稳态转换理论描述了非线性系统中系统状态与驱动力的关系, 认为在生态系统具有较高抵 抗力的时候,生态系统表现出稳定的特征, 抵御外界干扰的能力较强. 只有在较强外力作用下, 生态系统状 态才可能发生大的改变; 而在生态系统抵抗力较低的时候, 生态系统对外力的影响更为敏感和脆弱, 在这种 情况下即使很小的外力作用, 系统也会发生突变并进人另外一个稳定状态. 生态系统突变往往伴随着生态 系统服务功能的巨大转变, 例如水体蓝藻暴发引起的水质急剧下降. 对生态系统稳定性的研究已经成为目前 国际相关研究的热点, 相关研究, 包括模型模拟 ${ }^{[2]}$ 、实验室实验 ${ }^{\left[{ }^{[}\right]}$和野外调查 ${ }^{[4-5]}$ 等陆续开展, 并开始逐步探 讨生态系统的多稳态特征、抵抗力、突变早期信号等.

湖泊生态系统是典型的复杂动态系统 ${ }^{[6]}$, 明确的反馈机制和相对封闭的自然条件使其在复杂动态系统 研究方面具有突出地位. 在长期人类活动干扰之下, 全球很多湖泊都面临的突出的环境问题, 例如富营养化 和湖泊酸化. 湖泊服务功能的丧失促使湖泊管理者花费大量精力在湖泊治理方面, 然而, 很多治理往往收效 甚微, 促使科学家更加深人地了解湖泊生态系统内部各要素之间动态变化的关系, 揭示湖泊生态系统的弹 性变化范围. 线性思维的湖泊生态系统演变特征的研究已不能为生态系统管理提供完全可靠的建议, 了解 湖泊生态系统结构的变化是理解湖泊生态系统突变的关键, 而系统行为的长期变化趋势是理解系统结构变 化的基础 ${ }^{[1]}$. 现代湖泊监测数据在时间尺度上有限, 限制了生态系统结构变化的研究. 湖泊沉积物是水生生 态系统长期变化的重要载体 ${ }^{[7]}$, 硅藻是水体中初级生产力的重要组成部分, 在生态系统动态变化中处于关 键位置, 其属种组合特征对水环境变化敏感且能较好保存在沉积物中, 是指示水生生态系统状态变化的有 效指标. 因此,本研究选择硅藻作为湖泊生态系统状态的替代指标.

长江中下游浅水湖泊发育于洪泛平原, 营养本底值较高. 该区人口密集,一直是中国经济、社会、文化的 中心地带, 人类生产活动对自然环境改造程度很大. 近代以来长江中下游湖泊发生不同程度的富营养化, 一 些湖泊生态系统状态发生了明显的转变, 服务功能明显退化, 对区域社会和经济的可持续发展产生了严重 阻碍. 同时, 由于具有完整的富营养化过程, 本区域浅水湖泊是研究生态系统突变的理想对象. 本文以长江中 游太白湖作为研究对象, 通过综合该湖已有的沉积记录和历史资料, 分析近百年来太白湖生态系统突变过 程,探讨不同人类活动方式对湖泊生态系统的影响以及湖泊生态系统的反馈机制.

\section{1 研究区概况}

太白湖 $\left(29^{\circ} 56^{\prime} \sim 30^{\circ} 01^{\prime} \mathrm{N}, 115^{\circ} 46^{\prime} \sim 115^{\circ} 50^{\prime} \mathrm{E}\right.$, 图 1), 是长江中下游洪泛平原湖泊群中的一个小型浅水 湖泊, 面积约 $25 \mathrm{~km}^{2}$, 水深 $3.2 \mathrm{~m}$, 位于中国湖北省黄冈市黄梅、武穴两县市交界处, 华阳河水系中上游, 流域 面积 $607 \mathrm{~km}^{2}$. 太白湖除接纳本流域来水外, 汛期西承武山湖来水, 全部湖水从南部向东由梅济闸泄人龙感 湖后再经华阳大闸排至长江, 湖盆底部平坦, 是一个典型的过水型浅水湖泊. 湖泊位于大别山南麓伸延的低 山丘陵与长江冲积平原交界地带, 沿流域依次分布有构造剥蚀低丘、更新世网纹红土及砂砾石等组成的阶 地和开阔的全新世冲积平原, 北部有残丘深人, 岸线曲折, 湖泊南部岸线平直 ${ }^{[8]}$. 太白湖流域地处亚热带季 风区, 年均温度 $18.4^{\circ} \mathrm{C}$, 多年平均降水 $1273 \mathrm{~mm}$, 蒸发量 $1041 \mathrm{~mm}^{[9]}$, 水热条件好, 流域人口众多, 经济发达, 国民经济以农业为主.

根据《太白湖水产资源综合考察报告》 ${ }^{\mathbb{1} 、}$ 《黄冈市水资源评价和开发利用》 ${ }^{2}$ 、统计年鉴和相关论文等资 料记载, 近百年来太白湖在水系连通、湖泊形态、人口承载、营养输人和鱼类组成以及养殖方式上都发生了 较大改变 (图 2). 在水系连通方面, 1955 年太白湖下游建成梅济新闸, 修闸后湖水通过梅济港向东排人龙感 湖后进人长江, 水位直接受梅济堤闸人工调控, 减小了江水倒灌对太白湖的影响. 1958-1963 年间太白湖上 游陆续建成了仙人坝水库、考田水库、荆竹水库 ${ }^{[9]}$, 使湖泊水动力减弱. 1976 年上游武山湖与太白湖之间修 建童司牌闸, 非汛期港道处于闸断状态, 进一步阻隔了太白湖与长江的流通关系. 另外, 建国后太白湖被严

(1)《太白湖水产资源综合考察报告》为 “江汉平原水产资源考察”科研项目编写的内部考察报告,未公开发表.

(2)《黄冈市水资源评价和开发利用》为黄冈市水利局编写的内部调查报告,未公开发表. 


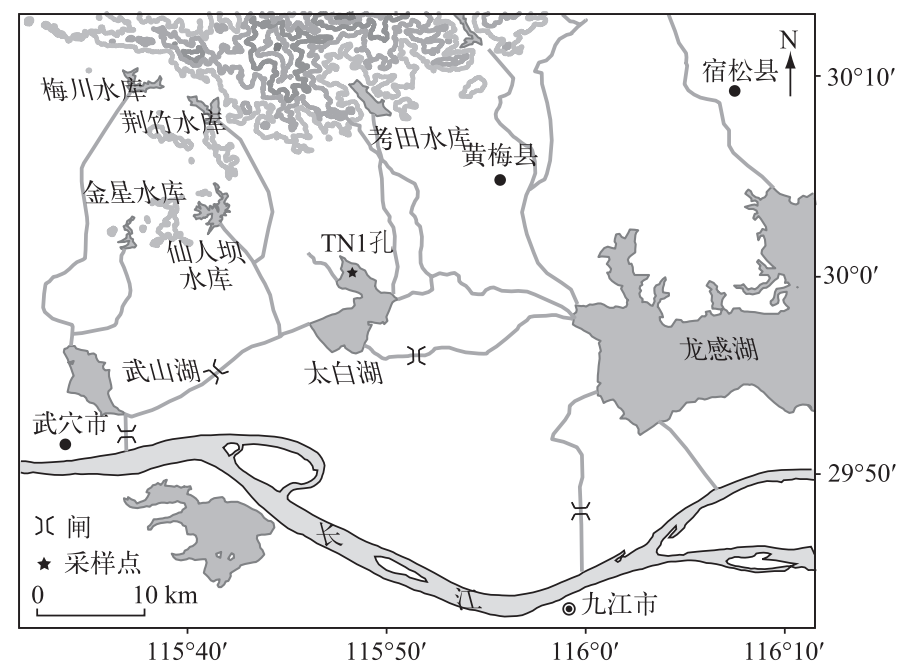

图 1 长江中游太白湖研究区和采样点示意

Fig.1 Lake Taibai and sampling situation in the middle reach of Yangtze River

重围脣, 由于水浅底平, 湖面面积和形状都发生了较大改变. 据统计, $1930 \mathrm{~s}$ 太白湖水面面积有 $44 \mathrm{~km}^{2}, 1950 \mathrm{~s}$ 东部围隔杨柳湖, 西南围层成万丈湖农场, 1960s 初太白湖面积缩减为 $38.1 \mathrm{~km}^{2}$, 经 $1970 \mathrm{~s}$ 进一步围湖造田, 现只剩下 $25 \mathrm{~km}^{2}$ 水面.

太白湖流域的人口数量自二十世纪以来一直逐渐增加, 1908 年流域三县 (黄梅、武穴和宿松县) 人口总 和为 94 万人, 到 1949 年已增至 114 万人, 1960 年后增长幅度明显提高, 2006 年流域人口达到 254 万人 ${ }^{[10]}$. 人口增加使得对粮食产量的需求增加. 1960s 起长江中下游流域周边农业生产中逐渐引人化肥, 1978 年改革 开放后, 全国化肥施用量以年均 $8.09 \%$ 的速度增长; 1997 年全国粮食作物化肥施用量达到 $2.9 \times 10^{10} \mathrm{~kg}$, 较 1978 年 $6.7 \times 10^{6} \mathrm{t}$ 增加了 3.38 倍 ${ }^{[11]}$. 在渔业养殖方面, 1954 年成立太白湖渔场后, 由于西边的武山湖从长江 灌江纳苗时, 鱼苗可从武山湖通过童司牌港到太白湖, 因而一直为放养湖泊, 养殖场投放的鱼苗较少, 1970s 初有鱼类 70 多种; 自 1976 年童司牌闸建成后,太白湖鱼类种类急剧减少, 1983 年有鱼类 46 种. 为了提高产 量, 渔场采取集约式养殖方式, 调整养殖结构, 增加了滤食性鱼种; 1995 年投放滤食性鱼类占到总投放重量 的 63\%, 并围网养鱼, 定量施肥投饵培肥养鱼, 投放大量草鱼 (Ctenopharyngodon idellus)、扣蟹 (Eriocheir sinensis) 去除水草转化为经济价值, 成鱼产量从 1981 年的 $2.0 \times 10^{5} \mathrm{~kg}$ 发展到 1990 年突破 $5.0 \times 10^{5} \mathrm{~kg}^{[12]}$; 1996 年全年湖内投放碳酸氢铵 $3.0 \times 10^{5} \mathrm{~kg}$, 磷肥 $2.0 \times 10^{5} \mathrm{~kg}$, 草 $5.0 \times 10^{5} \mathrm{~kg} .1997$ 年为了保证渔业产量, 提高 了太白湖最低水位线 (从1987 年 $13.5 \mathrm{~m}$ 到 $13.6 \mathrm{~m}$ ) 和汛期水位 (从 $13.8 \mathrm{~m}$ 到 $14 \mathrm{~m}$, 湖底高程 $12.3 \mathrm{~m}$ ), 并在 每年 7、8 月启闸引江河水人湖, 以改善水质并引人长江天然鱼苗, 使鲌 (Culter alburnus)、鲂 ( Carnis megalobramae)、鱤 (Elopichthys bambusa) 等野生名贵鱼种增产 ${ }^{[10]}$. 但是在多年的过度化肥养鱼和从武山湖流人的 污水影响下,近年来太白湖已发生富营养化, 2001 年湖水透明度下降至 $0.4 \mathrm{~m}^{[13]}$, 年均总磷浓度达 125 $\mu \mathrm{g} / \mathrm{L}^{[14]}$.

\section{2 材料和方法}

2007 年 5 月在太白湖北部湖区中心采集了 $153 \mathrm{~cm}$ 长的柱状沉积岩芯 ( TN1 孔), 采样点位置为 $29^{\circ} 59^{\prime} 44.3^{\prime \prime} \mathrm{N}, 115^{\circ} 48^{\prime} 26.5^{\prime \prime} \mathrm{E}$ (图 1). 沉积岩芯以 $0.5 \mathrm{~cm}$ 间距分样. TN1 孔的年代序列根据 ${ }^{210} \mathrm{~Pb}$ 年代建立. 测年在中国科学院南京地理与湖泊研究所湖泊与环境国家重点实验室完成, 采用 CRS ( Constant Rate of ${ }^{210} \mathrm{~Pb}$ Supply) 年代模式进行计算, $42.5 \mathrm{~cm}$ 以下年代基于平均沉积速率外推计算 ${ }^{[15]}$. 硅藻样品取样间距在岩芯上 部 $20 \mathrm{~cm}$ 为 $0.5 \mathrm{~cm}, 20 \mathrm{~cm}$ 以下间距为 $1 \mathrm{~cm}$, 共鉴定了 87 个样品 ${ }^{[16]}$. 沉积物中硅藻样品分析采用盐酸和双氧 水处理 ${ }^{[17]}$, 属种鉴定依据 Krammer 和 Lange-Bertalot 的分类系统 ${ }^{[18]}$, 在 1000 倍生物显微镜下进行鉴定,一般 


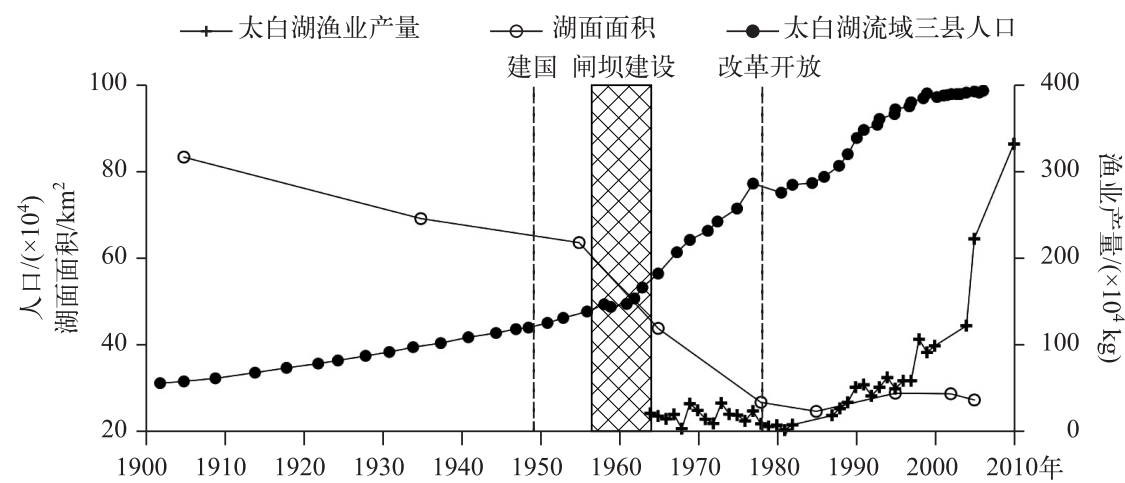

图 2 太白湖流域变化历史和重要事件

Fig. 2 History of Taibai Basin and important events on time scale

可鉴定到种级水平, 每个样品硅藻壳体统计至少在 300 粒以上,属种丰度按照百分比表示. 硅藻百分比图谱 使用 Tilia 程序, 属种组合带划分基于 CONISS 聚类分析. 选取 1850-2006 年间的 63 个硅藻样品数据进行湖 泊生态系统状态代表分析.

对于时间序列上系统状态突变点的检测, 本研究采用 Rodionov 提出的检测平均水平显著变化的 STARS (Sequential T-test Algorithm for Analyzing) 突变检测 ${ }^{[19]}$ 和 R 语言平台的 Strucchange 系统结构变化检测包 ${ }^{[20]}$. 沉积物中硅藻数据变化使用主成分分析 (Principal Components Analysis, PCA) 以提取硅藻群落变化的主要信 息. 根据排序计算的原理,先用降维对应分析 (Detrended Correspondence Analysis, DCA) 计算轴长以估计群落 组成的异质性, 结果显示 DCA 排序前 4 个轴长度都小于 3 , 说明物种分布变化同质性较高, 符合主成分分析 PCA 的线性假设 ${ }^{[21]}$, 故使用 PCA 第一轴得分代表生态系统状态的主要变化趋势, 通过 STARS 计算得到硅 藻群落时间序列上的突变点. 在 Excel 中加载 STARS 模块进行分析, 本次研究参数设置显著度 0.05 , 步长 (Cut-off length) 为 5 ,通过计算结果 Regime Shift Index (RSI 指数)来表示突变显著度大小. Strucchange 算法 为用线性回归模型进行连续 $\mathrm{F}$ 检验分析突变点, $\mathrm{F}$ 统计值峰值的出现标志着系统结构的重新组织 ${ }^{[20]}$. 参考 两个方法的计算结果,得出太白湖生态系统状态是否发生突变以及发生突变的时间的结论.

\section{3 结果}

\section{1 化石硅藻组合和理化指标记录}

沉积物中共鉴定出 40 个硅藻属种, 参考聚类分析结果和主要变化特征划分出三个组合带 (图 3 ), 具体 变化特征如下:

组合带 I ( 1850-1956 年, 42.5 19.5 cm) 中浮游种颗粒直链藻 ( Aulacoseira granulata) 和底栖种尖布纹藻 (Gyrosigma acuminatum) 为主要优势组合, 期间, 尖布纹藻的百分含量随时间不断增加而颗粒直链藻的百分 含量逐渐减少. 其他种如萎形短缝藻 (Eunotia pectinalis)、椭圆双壁藻 (Diploneis elliptica) 、羽纹藻属 (Pinnularia sp.) 等也有零星分布(共占约 10\%), 但变化趋势并不明显.

组合带 II ( 1956- 1995 年, 19.5 7.5 cm) 总的特征是附生种与底栖种占优势, 浮游种颗粒直链藻含量明 显减少, 典型富营养种高山直链藻 (Aulacoseira alpigena) 和可疑环冠藻 (Cyclostephanos dubius) 开始出现, 附 生种尖布纹藻成为优势种 ( $30 \% \sim 38 \%$ ), 蓖形短缝藻含量减少并消失, 但谷皮菱形藻 (Nitzschia palea)、针状 菱形藻 (Nitzschia subacicularis)、舟形藻属 (Navicula sp.) 等属种都有显著增加, 底栖种的增多指示湖水透明 度的上升,附生种增多代表水生植物生物量的增加.

组合带 III ( 1995-2006 年, 7.5 0 cm) 为尖布纹藻和颗粒直链藻组合过渡到谷皮菱形藻、尖布纹藻、颗粒 直链藻和针状菱形藻等多优势种的阶段. 颗粒直链藻逐渐减少至小于 $20 \%$ 而富营养浮游种可疑环冠藻、谷 皮菱形藻等在本阶段增多,指示此阶段营养盐浓度升高.

在太白湖的沉积物理化指标中, 总有机碳 (TOC) 和中值粒径随时间变化幅度较明显. 在富营养湖泊中, 
总有机碳含量基本代表了湖泊内源初级生产力水平 ${ }^{[22]}$, 粒度能够间接反映水动力条件的变化 ${ }^{[23]}$, 当中值粒 径减小时, 说明湖中悬浮颗粒增多, 水动力减弱. TN1 孔中总有机碳含量在组合带 II 和组合带 III 中快速增 长, 指示了 1956 年后有机质的加速积累; 中值粒径在 1956 年后显著降低,显示水动力强度下降 (图 3).

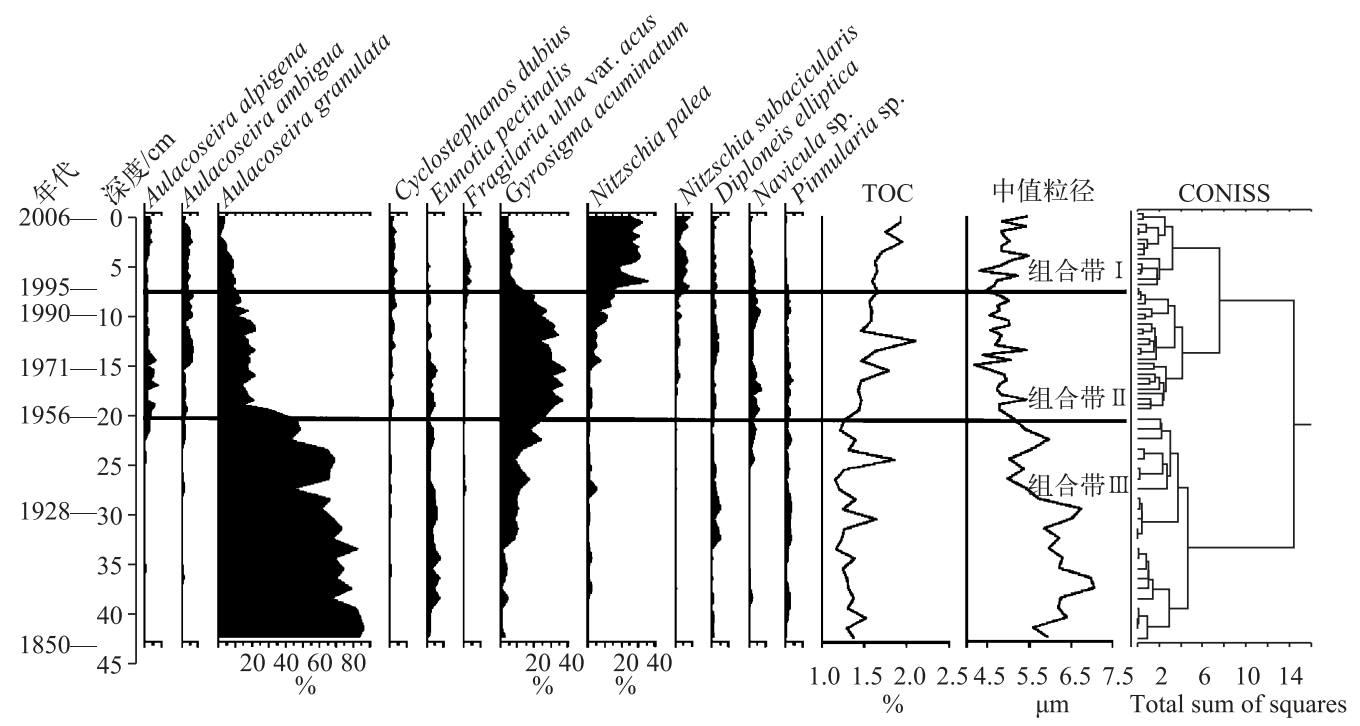

图 3 太白湖 TN1 孔硅藻群落、TOC 和中值粒径的变化趋势

Fig. 3 Trends in percentage of main diatom species, sediment TOC and

Median grain size in northern Lake Taibai sediment core(TN1 core)

\section{2 太白湖生态系统突变}

对硅藻样品进行 PCA 分析,结果表明第一轴解释的硅藻数据信息量为 $80 \%$,第二轴解释的信息量为 17\% (图 4a),PCA 第一轴变化趋势大致反映了硅藻群落变化的主要特征. 以 1958 年为界, 前后两个时间段 里硅藻群落组合特征差异非常显著. 基于硅藻群落 PCA 第一轴得分, STARS 方法检测突变共显示了 4 次变 化, 分别在 1927、1947、1958 和 2001 年附近 (图 4c), 其中 1958 年附近的变化最为显著, RSI 指数明显, 为 -2.04. 1930 年前生态系统状态较为平稳, 显著的变化发生在 1947- 1958 年期间, 2 个较小 $R S I$ 指数值的突 变发生在 1927 年和 2000 年附近. 利用 Strucchange 测试得到的显著突变点在 1956 年附近, 与 STARS 检测方 法中 RSI 指数最大值所处的 1958 年前的突变点相符合, 因此可以进一步确认太白湖生态系统在 1960s 附近 发生突变.另外,2001 年左右由 STARS 方法检测出的突变点, 对应硅藻组合在 1990s 发生的快速转变, 反映 出该时段湖泊生态可能发生了重要转变, 但是由于目前缺少 2001 年之后较长时间的古湖沼数据, 还有待进 一步研究确认系统是否发生系统状态转变.

\section{4 讨论与结论}

\section{1 生态系统突变原因分析}

湖泊生态系统状态变化往往是由外界驱动力变化, 如水动力、营养条件、气候变化等因素综合作用的结 果.太白湖 TN1 孔上部岩芯的硅藻纪录揭示,生态系统显著的突变发生在 1950s 未期, 而 1956 年附近中值粒 径的下降, 相应地指示了修闸筑坝导致江湖关系的改变 ${ }^{[24]}$. TOC 含量显著上升, 显示流域营养物质输人的 增加和水文条件的改变, 造成湖水滞留时间变长和营养盐积累增多, 促进了浮游植物与水生植物的生长, 快 速提高了湖泊的初级生产力, 从而使太白湖生态系统状态产生巨大转变. 摇蚊记录研究表明, 1960s 后太白 湖中摇蚊属种由适应中营养的摇蚊属种逐渐向耐营养属种转变, 辅证了湖中营养盐的富集 ${ }^{[25]}$. 不难看出, $1950 \mathrm{~s}$ 末期太白湖生态系统突变产生的主要原因是外力驱动下湖泊水动力条件改变造成的. 在 $1950 \mathrm{~s}$ 建造闸 坝之前, 太白湖江湖连通, 营养水平相对较低, 气候因素, 尤其是降水的波动对湖泊生态系统影响非常大, 对 
应图 4c 中 PCA 第一轴得分在 1950 年前频繁波动; 1950s 之后,水文条件的巨大突变使得江湖关系从根本上 改变, 由于太白湖上游水库的存在, 降水对湖泊的影响被大大削弱. 1990s 后长江流域逐渐升温与流域营养 的不断增加,共同促进湖泊营养水平的提高,对太白湖生态系统富营养化进程有重要影响.
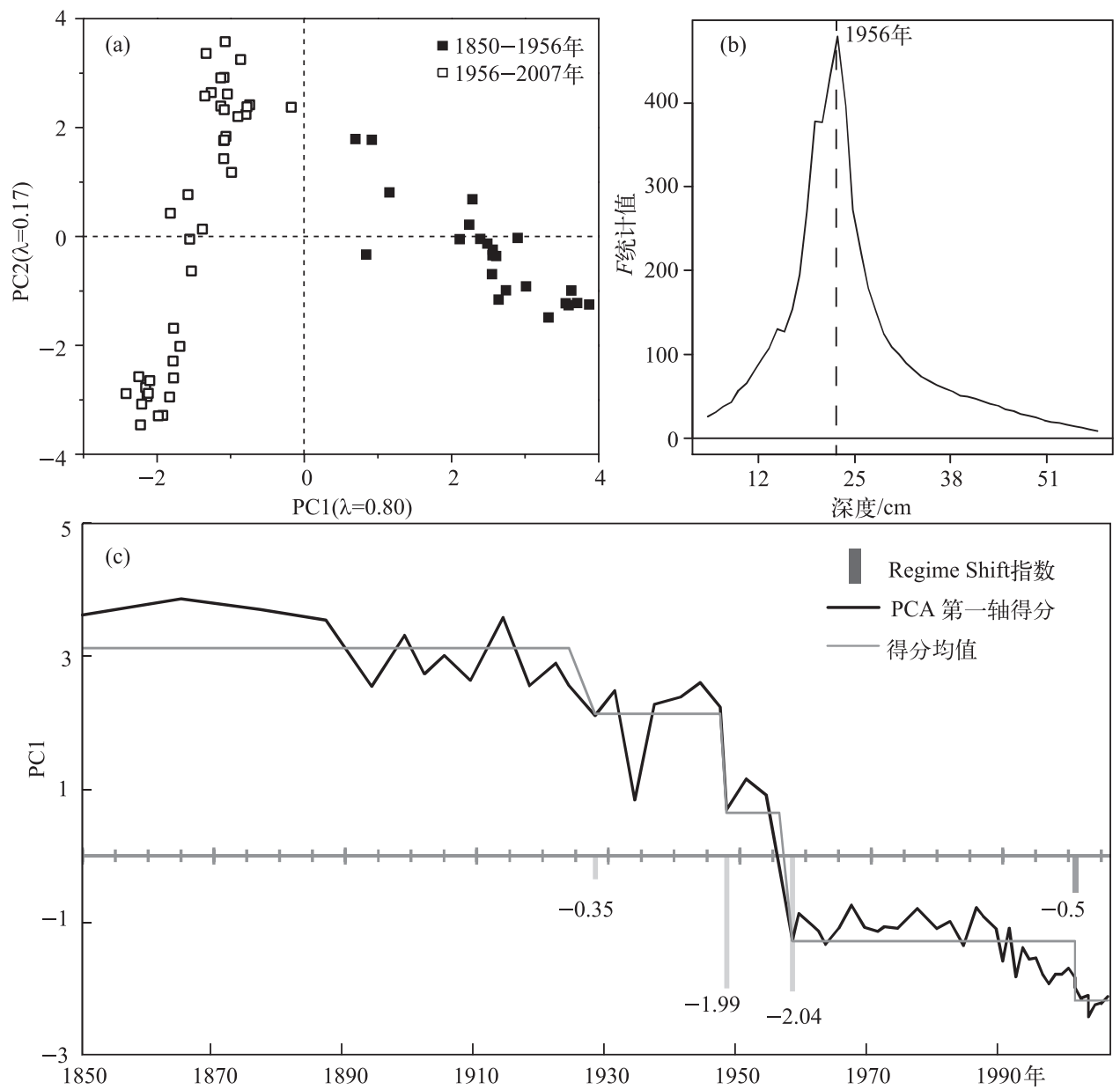

图 4 太白湖硅藻 PCA 双轴图及第一轴得分的突变过程检测结果

( $\mathrm{a}$ : 钻孔硅藻样品 PCA 排序结果; $\mathrm{b}: \mathrm{F}$ 检验测试的生态系统突变点; $\mathrm{c}: \mathrm{T}$ 检验检测的生态系统突变过程)

Fig.4 Biplot of fossil diatom PCA analysis and regime shift detection results in PC1 score (a: Biplot of fossil diatom PCA analysis in TN1 core; b: Strucchange point detected in F-test; c: Regime shifts detected through T-test )

湖泊生态系统状态的改变不仅受外界驱动力影响, 也与生态系统内部各要素之间的反馈机制密切相关. 通过对湖泊环境历史资料和沉积物古生态数据的整合, 本研究结合湖泊富营养化特点, 提取太白湖生态系 统中重要组成部分, 包括非生物环境要素 (如水动力、浊度和营养水平等) 以及生物组分 (如浮游植物、浮游 动物、沉水植物、节肢动物、鱼类等) 的数据信息, 将近百年来太白湖生态系统内部各主要要素的关系强弱变 化通过要素间连接线的粗细表达出来,绘制出生态系统不同阶段各要素相互作用关系示意图 (图 5), 对不同 时期内部机制进行定性的探讨.

\section{2 生态系统转变过程}

阶段 $1: 1900-1958$ 年. 根据历史记载, 1958 年之前太白湖已经成为当地水产农业的重要产地 ${ }^{[26]}$,但人 


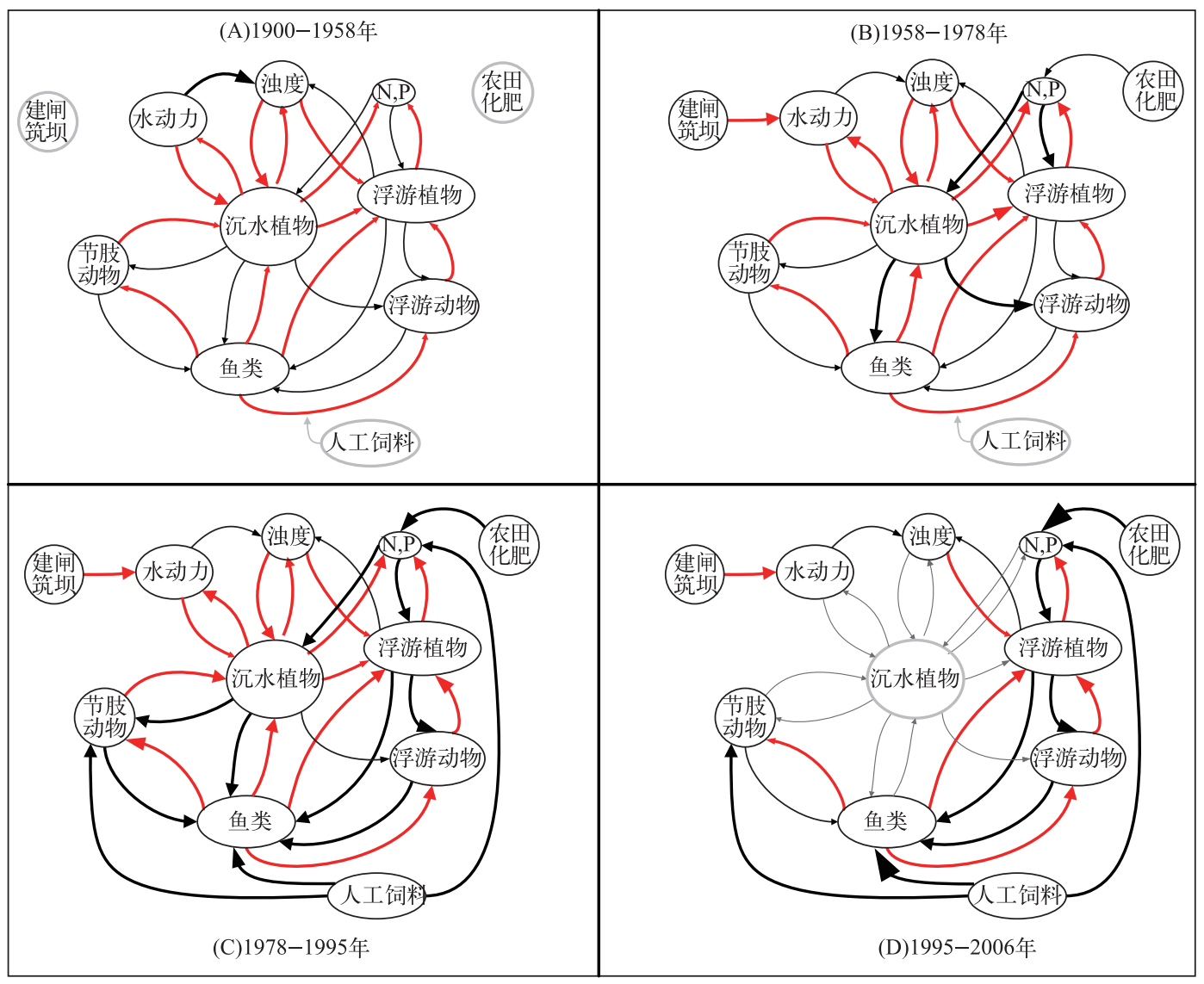

图 5 近百年太白湖生态系统反馈关系变化示意(黑箭头表示因果作用的同向连接; 红箭头表示因果关系的反向连接;线条粗细表示因果关系强度相对变化,越粗表示强度越大)

Fig.5 Feedbacks and links in Lake Taibai ecosystem changing over the past century

(Black arrows are positive effects on the end object; red arrows are negative effects on the end object; thickness of lines refers to comparative strength of the links )

类活动尚不强烈, 湖水西南通过武山湖, 东南通过龙感湖与长江自由联通, 营养水平相对较低, 粒度记录指 示当时水动力较强, 对于水生植物扎根和光合作用不利. 此时湖泊植被覆盖度较低, 硅藻群落组成以浮游种 类为主要优势种 (图 3). 鱼类多为长江洄游到湖泊中的野生品种, 多样性较高 ${ }^{\mathbb{D}}$. 整个生态系统种类组成较 为复杂, 是一个较为稳定的自然系统 (图 $5 \mathrm{~A}$ ).

阶段 $2: 1958-1978$ 年. 1958 年后, 在太白湖出水口建闸和上游来水处建坝拦水库来蓄水防洪,使湖水流 通性下降, 换水周期变长, 流速减缓, 改变了湖泊水动力状况. 由沉积物粒度的变化可以看出, 这段时期开始 湖泊水动力减弱, 有机质及营养盐的流域滞留时间变长. 由于 $1960 \mathrm{~s}$ 起开始广施化肥 ${ }^{[27]}$, 从湖泊周围耕地流 人湖中的营养盐增多, 湖水中营养盐含量积累. 稳定的水文条件以及营养的富集, 促使了沉水植物生长, 从 而加强沉水植物对湖泊生态系统的影响. 这一时期狍粉数据表明, 营养的增加促使湖泊初级生产力的上升, 浮游植物和沉水植物生长繁盛. 硅藻群落组成显示, 这一阶段附生硅藻含量较高, 说明湖泊沉水植物覆盖度 较高. 在营养增加和水动力变缓的共同作用下, 沉水植物的生长致使系统中沉水植物、浊度、浮游藻类之间的 正反馈机制得以加强( 图 5B), 使得湖泊水体处于水草丰富的清澈状态.

(1) 参考《太白湖水产资源综合考察报告》,1983. 
阶段 3:1978-1995 年.改革开放后,陆地面源污染和水体化肥是本阶段的主要营养输人. 在上游长江通 道被闸断的情况下, 太白湖人工投放大量鱼苗养殖, 将滤食性鱼类比重增加到 $60 \%$ 左右, 并进行人工肥水和 饵料投喂; 耕地施用化肥的用量直线上升 ${ }^{[10]}$, 沉积物磷趋于饱和, 水体中的活性营养盐急剧增加 ${ }^{[14]}$, 刺激浮 游植物大量生长, 致使湖水浑浊, 抑制了沉水植物光合作用, 导致了沉水植物覆盖度开始降低. 同时, 由于管 理者认为水草生长不利于渔业产量 ${ }^{[26]}$, 投放大量扣蟹、鳌虾和草鱼用于增加收人并遏制水草的生长. 湖泊中 食草鱼类产量增加, 沉水植物被大量食用, 节肢动物在底层受食有机碎屑的同时夹断大量水生植物根系 ${ }^{[13]}$, 导致沉水植物逐渐减少. 本阶段在外界营养的不断增强的作用下, 各要素之间的相互作用关系不断加强. 主 要表现为浮游植物的生长开始致使沉水植物-浮游动物-浮游植物之间的正反馈机制不断加强 (图 5C), 致 使沉水植物开始减少, 湖泊也逐渐从清澈状态变成混浊状态.

阶段 4:1995-2006 年.1995 年太白湖渔场养殖技术上调整鱼种结构以鲢鳙为主的滤食性鱼类, 并搭配 套养鲭鱼、乌鳢和青鱼以及吊养珍珠蚌等经营项目 ${ }^{[12]}$, 每年投人大量鱼苗进行 1 2 年周期的养殖作为主要 经济鱼种, 同时大量施肥投饵, 渔业产量急剧增加.太白湖沉水植物多样性和丰富度都显著减少, 在 2001 年 水生生物调查中, 沉水植物优势种如轮叶黑藻 (Hydrilla verticillata)、马来眼子菜 (Potamogeton malaianus)、金 鱼藻 (Ceratophyllum demersum) 和穗花狐尾藻 (Myriophyllum spicatum) 已经消失, 只有密齿苦草 (Vallisneria denseserrulata) 由于具有繁殖能力强的地下根状茎和越冬块茎而能适应人为干扰,一度达到 $73 \%$ 的覆盖度, 但是生物量很少 ${ }^{[13]}$. 在 2014 、2015 年笔者野外考察时太白湖的沉水植物已经完全消失, 生态系统水质调节 功能进一步下降. 同时, 太白湖生态系统结构逐渐变得单一, 捕食关系以食浮游生物鱼类-浮游生物关系为 主 (图 5D). 气候变暖和外源营养物质的增加共同不断提高湖泊水体的营养水平, 导致浮游植物的大量生 长, 使该湖泊成为重富营养化水体. 为了稳定和提高鱼类产量, 太白湖损失了生态系统水质调节功能, 致使 水质条件恶化.

\section{3 突变过程研究对生态系统管理的意义}

由上述分析可以看出, 湖泊生态系统状态不仅受到外驱动力大小的限制, 而且也受到生态系统内部各要 素反馈机制的影响. 太白湖湖泊生态系统状态在过去百年内的变化受制于沉水植物-浮游植物-浮游动物 - 鱼 类的相互作用关系. 外源营养的输人以及水文水动力条件的改变在改变单个要素的同时, 也深刻改变了各 要素之间相互作用关系的方式和强度. 人类社会对湖泊生态系统服务的需求决定了不同的人类活动方式. 然 而, 由于内部反馈机制的存在, 对湖泊生态系统某一部分服务的索取, 往往会忽略其它服务的变化. 可持续 发展的生态系统管理要求生态系统服务的获取不以其它服务的下降为代价,或者生态系统具有较强的抵抗 力, 能够修复外界干扰的影响. 对于湖泊生态系统管理者来说, 如果不考虑系统内部复杂的动态过程, 忽略生 态系统服务之间的相互作用关系, 新的问题会不断涌现.例如, 长江中下游地区湖泊中, 对湖泊渔业产量这一 供给服务的不断索取, 导致了很多湖泊水质调节服务的不断下降. 另一方面, 本研究揭示了太白湖在富营养 化过程中, 系统结构趋于简单, 导致生态系统抵抗力下降, 从而出现突变. 类似的现象在长江中下游地区普 遍存在, 例如汉江流域湖泊生物多样性在逐渐下降, 东湖在 $1950 \mathrm{~s}$ 浮游植物有 111 个属, 1980s 只有 57 个属, 水生维管束植物由 $1960 \mathrm{~s}$ 的 83 种降到 $1980 \mathrm{~s}$ 的 50 种; 洪湖的人江通道阻隔后野生鱼类种类由 100 多种减少 至 74 种, 到 1982 年湖内实际生存鱼类只有 31 种 ${ }^{[28]}$; 在长江下游, 由于过度捕捞和湖泊环境恶化, 太湖鱼类 的物种数量也不断下降, 优势种组成发生较大变化, 渔业资源小型化趋势明显, 鱼类群落生物多样性指数均 表现偏低 ${ }^{[29]}$,近 50 年主要生物指标表明太湖在 1990-1995 年间发生了稳态转换 ${ }^{[30]}$. 这些现象从侧面说明 了长江中下游湖泊生态系统的复杂性正在消失. 虽然目前人们对湖泊生态系统的认识有限, 未能全面建立 生态系统复杂性和抵抗力之间的关系, 本文研究表明维持湖泊生态系统的复杂性能够提高生态系统的抗干 扰能力. 湖泊作为典型的复杂动态系统, 不考虑内部各要素作用关系的开发利用, 会产生更多的环境问题. 综上所述, 在考虑系统中单个要素的长期变化趋势之时, 应该充分考虑系统各要素之间的反馈状况, 对湖泊 生态系统服务的管理应该建立在充分了解湖泊生态系统动态变化过程的基础之上.

\section{4 结论}

1) 过去 150 年来,太白湖硅藻特征主成分变化反映的湖泊生态系统状态转变揭示了在 $1950 \mathrm{~s}$ 末发生的 湖泊生态系统状态突变. 该突变主要是由于江河阻隔导致的水文水动力条件改变所造成的. 
2) 在 1990s 之后, 由于外源营养不断输人以及湖泊生态系统内部反馈机制的调整, 水质变差, 沉水植物 消失, 导致湖泊生态系统结构趋于单一, 系统弹性下降.

3 ) 为了可持续地利用湖泊,防止生态系统突变的发生, 湖泊生态系统服务管理者应了解系统动态变化 过程, 考虑生态系统反馈机制对生态系统服务的影响.

\section{5 参考文献}

[ 1 ] Meadows D, Wright D eds. Thinking in systems: A primer. White River Junction, USA : Chelsea Green Publishing, 2008 : 127-130.

[ 2 ] Scheffer M, Carpenter SR, Lenton TM et al. Anticipating critical transitions. Science, 2012, 338( 6105) : 344-348. DOI: $10.1126 /$ science. 1225244 .

[ 3 ] Dai L, Vorselen D, Korolev KS et al. Generic indicators for loss of resilience before a tipping point leading to population collapse. Science, 2012, 336(6085) : 1175-1177. DOI: 10.1126/science.1219805.

[ 4 ] Wang R, Dearing JA, Langdon PG et al. Flickering gives early warning signals of a critical transition to a eutrophic lake state. Nature, 2012, 492(7429) : 419-422. DOI: 10.1038/nature11655.

[ 5 ] Carpenter SR, Cole JJ, Pace ML et al. Early warnings of regime shifts: A whole-ecosystem experiment. Science, 2011, 332(6033) : 1079-1082. DOI: 10.1126/science.1203672.

[ 6 ] Dakos V, Hastings A. Editorial: special issue on regime shifts and tipping points in ecology. Theoretical Ecology, 2013, 6 (3) : 253-254. DOI: 10. 1007/s12080-013-0197-1.

[ 7 ] Anderson NJ, Bugmann H, Dearing JA et al. Linking palaeoenvironmental data and models to understand the past and to predict the future. Trends in Ecology \& Evolution, 2006, 21(12) : 696-704. DOI: 10.1016/j.tree.2006.09.005.

[ 8 ] Li Xinmin. Hydrological attributes in Lake Taibai in Eastern Hubei province. Journal of Huazhong Normal University, 1986, 20 (4) : 102-109 (in Chinese with English abstract). [李新民. 鄂东太白湖的水文特性. 华中师范大学学报: 自 然科学版, 1986, 20(4) : 102-109.]

[ 9 ] Liu Enfeng, Yang Xiangdong, Shen Ji et al. Sedimentary flux of Lake Taibai, Hubei Province and correlations with precipitation and human activities in its catchment during the last century. J Lake Sci, 2007, 19(4) : 407-412(in Chinese with English abstract). DOI: 10.18307/2007.0408. [刘恩峰, 羊向东, 沈吉等. 近百年来湖北太白湖沉积通量变化与流域 降水量和人类活动的关系. 湖泊科学, 2007, 19(4) : 407-412.]

[10] Jin Huabing, Li Jie. An overview of fish multiplication technology in Lake Taibai. Directory in Fishery, 2014, 12: 16-18 (in Chinese). [ 金华兵，李洁. 太白湖鱼类增殖放流技术总结. 渔业致富指南，2014，12: 16-18.]

[11] Peng Lin. Process, prospect and distribution of fertilizer use and grain production in China. Research of Agricultural Modernization, 2000, 21 (1) : 14-18 (in Chinese with English abstract). [彭琳. 中国化肥施用与粮食生产的进程、前景与 布局. 农业现代化研究, 2000, 21(1) : 14-18.]

[12] Jin Huabin. High productivity and high benefits in lakes by new modes of aquaculture-a case study on Lake Taibai fishery in Huanggang city. Directory in Fishery, 2007, 8: 14-15(in Chinese). [ 金华兵. 不断创新养殖模式实现湖泊高产高 效——黄冈市太白湖渔场成鱼高产高效经验之总结. 渔业致富指南, 2007, 8: 14-15.]

[13] Jian Yongxing, Wang Jianbo, He Guoqin et al. A comparative study of aquatic plant diversity of Haikou, Taibai and Wushan Lake in Hubei Province of China. Acta Ecologica Sinica, 2001, 21(11) : 1815-1824(in Chinese with English abstract). [ 简永兴, 王建波, 何国庆等. 湖北省海口湖、太白湖与武山湖水生植物多样性的比较研究. 生态学报, 2001, 21(11) : 1815-1824.]

[14] Yang XD, Anderson NJ, Dong XH et al. Surface sediment diatom assemblages and epilimnetic total phosphorus in large, shallow lakes of the Yangtze floodplain: their relationships and implications for assessing long-term eutrophication. Freshwater Biology, 2008, 53(7) : 1273-1290. DOI : 10.1111/j.1365-2427.2007.01921.x.

[15] Liu Enfeng, Xue Bin, Yang Xiangdong et al. ${ }^{137} \mathrm{Cs}$ and ${ }^{210} \mathrm{~Pb}$ chronology for recent lake sediment—a case study of Chaohu Lake and Lake Taibai. Marine Geology \& Quaternary Geology, 2009, 29(6) : 89-94 (in Chinese with English abstract). [刘恩峰, 薛滨, 羊向东等. 基于 ${ }^{210} \mathrm{~Pb}$ 与 ${ }^{137} \mathrm{Cs}$ 分布的近代沉积物定年方法一以巢湖、太白湖为例. 海洋地质与 第四纪地质, 2009, 29(6) : 89-94.]

[16] Liu Q, Yang XD, Anderson NJ et al. Diatom ecological response to altered hydrological forcing of a shallow lake on the 
Yangtze floodplain, SE China. Ecohydrology, 2012, 5(3) : 316-325. DOI: 10. 1002/eco. 222.

[17] Battarbee R, Jones V, Flower R et al. Diatoms. In: Smol J, Birks J, Last W et al eds. Tracking Environmental Change Using Lake Sediments, Vol. 3: Terrestrial, Algal, and Siliceous Indicators. Dordrecht: Kluwer Academic Publishers, 2002: 155-202.

[18 ] Krammer K, Lange-Bertalot H. Bacillariophyceae(1-4 Teil). In: Süsswasserflora von Mitteleuropa, Vol. 2. Stuttgart/Jena: Gustav Fischer Verlag, 1986, 1988, 1991, 1991: 876, 610, 598, 437.

[19] Rodionov SN. A sequential algorithm for testing climate regime shifts. Geophysical Research Letters, 2004, 31 (9) : 1-4. DOI : 10.1029/2004GL019448.

[20] Achim Zeileis, Friedrich Leisch, Kurt Hornik et al. Strucchange: an R Package for testing for structural change in linear regression models. Journal of Statistical Software, 2002, 7(2) : 1-38. DOI: 10.18637/jss.v007.i02.

[21] Lepš J, Šmilauer P. Multivariate analysis of ecological data using CANOCO. Cambridge: Cambridge University Press, 2003: 51-54.

[22] Pirkko Kortelainen. Content of total organic carbon in Finnish lakes and its relationship to catchment characteristics. Canadian Journal of Fisheries and Aquatic Sciences, 1993, 50(7) : 1477-1483. DOI: 10.1139/f93-168.

[23] Ashley GM. Interpretation of polymodal sediments. Journal of Geology, 1978, 86(4) : 411-421. DOI: 10.1086/649710.

[24] Chen X, Yang XD, Dong XH et al. Environmental changes in Chaohu Lake (southeast, China) since the mid 20th century: The interactive impacts of nutrients, hydrology and climate. Limnologica, 2013, 43(1) : 10-17. DOI: 10.1016/j.limno.2012.03.002.

[25] Zhang Enlou, Cao Yanmin, Liu Enfeng et al. Chironomid assemblage and trophic level of Lake Taibai in the middle reaches of the yangtze river over the past 150 years. Quaternary Sciences, 2010, 30(6): 1156-1161(in Chinese with English abstract). [张恩楼, 曹艳敏, 刘恩峰等. 近 150 年来湖北太白湖摇蚊记录与湖泊营养演化. 第四纪研究, 2010,30 (6) : 1156-1161.]

[26] Zou Yi. Population time series of Longgan-Lake Taibai Catchment during 1391-2006 and its sediment response. Journal of Chinese Historical Geography, 2011, 26(3) : 41-59(in Chinese with English abstract). [邹怡. 1391-2006 年龙感湖太白湖流域的人口时间序列及其湖泊沉积响应. 中国历史地理论丛, 2011, 26(3) : 41-59.]

[27] Yang Xiangdong, Shen Ji, Xia Weilan et al. Diatom assemblages in sediment and dynamic process of lake trophic evolution from Longgan lake, east China. Acta Palaeontologica Sinica, 2002, 41(3) : 455-460. [羊向东, 沈吉, 夏威岗等. 龙感 湖近代沉积硅藻组合与营养演化的动态过程. 古生物学报, 2002, 41(3) : 455-460.]

[28] Gu Yansheng, Ge Jiwen, Huang Junhua et al eds. Climate change, human activities and evolution of Jianghan Floodplain lakes in the past 20 thousand years. Beijing: Geological Publishing House, 2009: 213-215. [顾延生, 葛继稳, 黄俊华 等. 2 万年来气候变化人类活动与江汉湖群演化. 北京: 地质出版社, 2009: 213-215.]

[29] Mao Zhigang, Gu Xiaohong, Zeng Qinfei et al. Community structure and diversity of fish in Lake Taihu. Chinese Journal of Ecology, 2011, 30(12) : 2836-2842. [毛志刚, 谷孝鸿, 曾庆飞等. 太湖鱼类群落结构及多样性. 生态学杂志, $2011,30(12): 2836-2842$.

[ 30 ] Xu DL, Cai Y, Wu XQ et al. Regime shifts and resilience of the lake Taihu social-ecological system under long-term external disturbance (1960s-2000s). CLEAN-Soil Air Water, 2014, 43(4) : 561-568. DOI: 10.1002/clen.201300870. 